\title{
Biogas appliances in Sub-Sahara Africa
}

\author{
Vianney Tumwesige ${ }^{a *}$ David Fulford ${ }^{b}$ Grant .C. Davidson ${ }^{c}$ \\ ${ }^{a}$ Green Heat (U) Ltd, P.O. Box 10235, Kampala, Uganda and Center for Research in Energy and Energy \\ Conservation, Makerere University; ${ }^{b}$ davidf@kingdombio.co.uk. ${ }^{c}$ The James Hutton Institute, \\ Craigiebuckler, Aberdeen, AB15 8QH, Scotland, UK \\ "Corresponding author: Vianney Tumwesige, Green Heat (U) Ltd, P.O. Box 10235, Kampala, Uganda. \\ Tel: (+256) 71237 9889. Email: trustvianney@gmail.com.
}

\section{ABSTRACT}

Biogas production technology has led to the growth of a number of biogas appliances for lighting, cooking, heating, incubating and electricity generation. The most commonly used appliance for cooking purposes in both households and institutions is the biogas stove. However, some households are using biogas lamps for lighting their homes. The overall objective of this paper is to review biogas appliances being used in the different National Biogas Support Programmes in Sub-Saharan Africa.

Several locally available biogas stoves were tested, but were found to have lower efficiencies than were acceptable. The stoves were not made according to basic gas stove theory.

Key questions are: what biogas appliances are being used; what are the major areas where appliances can be developed to improve their efficiencies; and what are the possible methods/mechanisms to do so? 


\section{Introduction}

Energy is an essential ingredient for socio-economic development and economic growth. In developing countries, around 2.6 billion people rely on traditional biomass such as fire wood, charcoal, animal dung and agricultural residues, while 400 million use coal as their primary cooking fuel. Over 700 million people without access to liquefied petroleum gas (LPG) and electricity for cooking live in the Least Developed Countries and over 600 million in Sub-Saharan Africa (1).

Traditional biomass such as wood fuel, agricultural residue and animal waste accounts for over 80 percent of energy use in Sub-Saharan Africa (2). Over 90 per cent of the energy used in households is for cooking and the rest of the energy is used for lighting (3). Ordinary kerosene lamps are the most common type of fuel-based lighting in developing countries (4). The light output of kerosene lamps varies from 10 to 100 lumen, depending on the type of lamps and the wicks used. The recommended level of illumination required for reading is $100-200 \mathrm{Im} \mathrm{m}^{-2}(5)$.

Global estimates of greenhouse gas emissions from fuel-based lighting places the value at 190 million tonnes of carbon dioxide $\left(\mathrm{CO}_{2}\right)$ per year (6). In Kenya, for example, 88 per cent of the population uses kerosene as a lighting source (7). While kerosene is the dominant fuel in practice, diesel is used when it is the cheaper alternative or where government programs limit the availability of kerosene (8). Despite efforts at rural electrification, the number of people without access to grid electricity is growing in SubSaharan Africa (9).This is attributed to the high cost of supplying rural and peri-urban households, population growth, weak implementation capacity, electricity generation shortage and lack of appropriate incentives (10).

Lack of access to clean and efficient fuels in homes can impact health in many ways. The most important direct health effects result from the air pollution caused by burning solid fuels, often indoors on open fires and simple stoves $(11,12)$. Over 1.6 billion people worldwide are exposed to particulate matter when lighting and burning carbon based fuel such as wood, dung, candles, kerosene, to conduct business, study, and perform household tasks after dark (6). The indoor use of inefficient stoves in households releases large amounts of smoke from incomplete combustion of solid fuels. Breathing this smoke affects the health of all members of the family, but especially that of women and their young children. While there is very little literature on the impact of installing biogas digesters on household air quality there is considerable evidence that homes burning traditional biomass fuels such as wood, charcoal, coal and dried crop/animal residues have very high concentrations of fine particulate matter and carbon monoxide (13). Evidence from studies homes in Nepal that burn charcoal and LPG suggests that fine particulate concentrations in homes using LPG were about one-tenth of the concentration of those in homes burning solid-fuels (14). It seems likely that similar order of magnitude reductions in indoor air pollutants could be experienced in homes switching from traditional biomass fuel to biogas systems. Significant improvements in respiratory and cardiovascular health of householders who experience such reductions in indoor air pollution concentrations can be anticipated, given results obtained from stove-based interventions in Guatemala $(15,16)$.

The energy deficit in poor households results in practical constraints, such as inadequate lighting (reliance on paraffin lamps, candles or wood fires), and inadequate cooking fuel and thus fewer hot, cooked meals. The problems caused by energy poverty in turn have consequences in the standard of living of the poor through more frequent illness (which impacts income), difficulty in doing schoolwork and so on (17). Access to clean and convenient energy services that can meet the needs of both lighting and cooking are therefore vital to the alleviation of poverty. Therefore, biogas could be an essential component for socio-economic development.

Biogas technology is an integrated waste management system (18) that is a clean, renewable, naturally produced and under-utilized source of energy. Biogas is produced in an air tight tank from a variety of substrates, such as animal manure, food waste, energy crops and industrial wastes. Anaerobic digestion is a multi-stage biological process, where the organic waste is mainly converted to a gaseous product 
composed of $50-70 \%$ (by volume) methane, $25-40 \%$ (by volume) carbon dioxide and traces of hydrogen sulphide, water vapour and ammonia (19-21).

Biogas energy has some advantages over other energy sources. Successful use of biogas technology can result, not only in energy generation and bio-fertilizer production, but also in other social and ecological benefits including improved sanitation from more efficient use of human and animal waste products, and reduction of imported fuel oil (22). The technology has the potential to contribute to mitigation of greenhouse gas emissions (23). Biogas systems lead to reduced enrichment of bodies of fresh water by runoff of inorganic plant nutrients from applied fresh-waste, reduced air pollution and improved utilization of crop nutrients (24). By eliminating the daily task of gathering firewood, biogas technology could reduce the work-load of women (25). Further, biogas is produced mainly from raw materials that are locally available and can be harnessed in controllable, containable and useable quantities.

The most efficient way to use biogas is in a heat-power combination where $88 \%$ efficiency is achievable, but this is only possible in larger installations and under the condition that the exhaust heat is used profitably (26). The efficiency of using biogas at smaller scale is $55 \%$ in stoves, $24 \%$ in engines and $3 \%$ in lamps

Biogas can lead to a reduction in greenhouse gas emissions by replacing fossil fuels; the carbon dioxide emitted following burning of biogas includes only carbon accumulated during the life cycle of plants and animals, and even without anaerobic digestion, this carbon would have been emitted over time by natural decomposition processes. Biogas can lead to large $\mathrm{CO}_{2}$ emission reductions in the electricity sector, by replacing fossil fuels and non-renewable fuels used in cooking or by substituting chemical fertilizer with bio-slurry (27). If an engine is run on biogas instead of diesel, generation of $1 \mathrm{~kW}$ of electricity would prevent $7,000 \mathrm{~kg} \mathrm{CO}_{2}$ per year being added to the atmosphere (28). Biogas can be used for all applications designed to run on natural gas. It can be used as a fuel in power generators, engines, boilers and burners.

The main use of biogas technology in the world is for domestic use in rural areas, where animal dung (mainly cattle or pig) is the main feed material. Small biogas plants are owned by individual farming families, who own a few animals, and who use the gas for cooking and also lighting. There are about 40 million such plants in China, about 4 million in India, about 1/4 million in Nepal and another $1 / 4$ million in the rest of Asia (29). Both China and India had national biogas programmes, initiated by their governments. The programmes in the rest of Asia were encouraged by the Netherlands Development Organisation (SNV). In 1993, SNV were asked to take over a biogas programme that had originally been set up in Nepal by Development and Consulting Services (DCS) of the United Mission to Nepal (UMN) in 1976 (30). DCS had developed their own design of biogas burner, which was cheaper than those commercially available from India or China. As SNV extended their biogas programme to other countries in Asia, this stove design has been copied and made by other manufacturers.

\section{Biogas burners}

\subsection{Biogas burner theory}

Biogas burns in oxygen to give carbon dioxide, water and energy content in methane is released. Understanding the combustion process provides a basis of performance criteria and emission standards used to regulate manufacturing and marketing of quality biogas stoves. Since the chemical reaction biogas burning is:

$$
\mathrm{CH}_{4}+2 \mathrm{O}_{2} \rightarrow \mathrm{CO}_{2}+2 \mathrm{H}_{2}
$$

and biogas contains $60 \%$ methane, while air contains $21 \%$ oxygen, the volume ratio for the stochiometric mixture of air and biogas is $5.7: 1$ or a volume fraction of $17.5 \%$. Biogas burns over a narrow range of mixtures from approximately $9 \%$ to $17 \%$ of biogas in air (30). If the flame has too much fuel, then it will burn incompletely, releasing carbon monoxide, which is poisonous, and soot particles. Therefore, the 
designs of appliances should aim at maximizing the conversion of methane into carbon dioxide in order to minimize the release of unburned methane and products of incomplete combustion. Stoves usually run with a small excess of air to avoid the danger of the flame becoming rich. If too much air is supplied, the flame cools off, thus prolonging the working time and increasing the gas demand (26).

Biogas stoves and other equipment are made in two parts: the burner itself, which mixes gas and air and feeds it to the flame ports, where it burns; and the frame within which it sits, which uses the flame to heat cooking pots or to generate light or use the heat in some other way. The frame for a stove supports the burner on legs and holds cooking pots the right distance away from the flame for effective heating.

\section{Figure 1: Parts of a biogas burner}

The burner itself has several parts (30). The amount of gas that flows into the burner is controlled by the jet, a hole which is carefully sized and defines the power output of the burner. Most burners are partially aerated, which means that the gas is mixed with a proportion of primary air that is less than optimum for combustion. The air and biogas are mixed and fed to a manifold which feeds the flame ports, where it burns. Secondary air flows around the outside of the flame ports to complete the combustion process. The burner ports are drilled into a shaped cap, which can be removed for cleaning, in case food gets spilled into the burner ports.

The optimum amount of air to allow a fuel gas to burn is called the stochiometric mix and is $5.5: 1$ for biogas. The flow of gas from the jet depends on the hole size and the gas pressure:

$$
Q=3.16 C_{d} A_{0} \sqrt{\frac{p}{s}} \times 1000 \text { in } \mathrm{dm}^{3} \mathrm{~s}^{-1},
$$

where $C_{d}$ is the coefficient of discharge of an orifice (jet), $A_{0}$ is the area of the jet $\left(\mathrm{m}^{2}\right), p$ is the gas pressure $(\mathrm{Pa})$, and $s$ is the specific gravity of the gas. Typical values of $C_{d}$ are between 0.7 and 0.9 , depending on how well it is made, $s$ is 0.94 for biogas. An average value of the enthalpy of combustion $(H$ - the heating value) of biogas is: $21.7 \mathrm{MJ} \mathrm{m}^{-3}$, so the power produced by a burner is simply $Q \times H$ or:

$$
P=3.16 H C_{d} A_{0} \sqrt{\frac{p}{s}} \times 1,000 \text { in } \mathrm{kW} \text { or } P=3.16 W C_{d} A_{0} \sqrt{p} \times 1,000,
$$

where $W=H / \sqrt{s}$ is called the Wobbe number of the gas $\left(=22.2 \mathrm{MJ} \mathrm{m}^{-3}\right)$.

As the gas emerges from the jet, it accelerates, which reduces the pressure according to Bernoulli's theorem:

$$
p+1 / 2 \rho v^{2}=\text { constant }
$$

where $p$ is the pressure (in $\mathrm{Pa}$ ), $\rho$ is the gas density $\left(\mathrm{kg} \mathrm{m}^{-3}\right.$ ) and $v$ is the gas velocity (in $\mathrm{m} \mathrm{s}^{-1}$ ). The reduced pressure entrains (draws in) air, which mixes with the gas in the mixing tube. The entrainment ratio $r$ is given by Priggs formula:

$$
r=\sqrt{s}\left(\sqrt{\frac{A_{t}}{A_{0}}}-1\right) \text { or } r=\sqrt{s}\left(\frac{d_{t}}{d_{0}}-1\right)
$$

where $A_{t}$ is the area and $d_{t}$, the diameter, of the throat, the narrowest part of the mixing tube. Typical values of $r$, which defines the primary aeration are between $50 \%$ and $75 \%$. The entrainment ratio is chosen to give an air flow to give a mix about twice that of stochiometric or theoretical air requirement. The mixing tube can be made as a venturi, with a narrow throat with tapers leading in and out, or as a straight tube. The length of a straight mixing tube should be at least $10 \times d_{t}$, the diameter, while a venturi tube can be $6 \times d_{t}$. The total flame port area $A_{p}$ should be between 1.5 and $2.2 \times A_{t}$ for Priggs formula to work.

\section{Figure 2: Parts of a gas flame}


The flame height at the flame ports are affected by the primary aeration. A low value of $r$ means the gas is seeking secondary air to burn, so the flames are long, "lazy" and do not burn properly. Poor combustion generates carbon monoxide, which is poisonous, and carbon particles (which show as red flashes in the flame). A high value of $r$ means that the gas can burn with the primary air, so the flames are much shorter. Full aeration is $(r=5.5)$ is inadvisable, as the flame can "flash back", i.e. jump through the flame ports, along the mixing tube and burn at the jet.

The flame ports need to be designed to allow easy access to secondary air flow. Various tricks are used to stabilise a flame, such as ledges around the flame ports and using small secondary flames around the main one. The potential heat contained in biogas can be released when sufficient quantity of air burns with it. Insufficient air would lead to loss of potential heat by incomplete combustion while an excess may give rise to an excessively large loss of potential heat. Biogas has a low laminar flame speed $\left(v_{f l}=0.25 \mathrm{~m} \mathrm{~s}^{-1}\right)(30)$. The flow in a flame port is turbulent, so the actual flame speed is higher. The velocity of the gas from the flame ports must be lower than the flame speed for the flame to be stable. Good mixing increases the flame speed, so improves flame stability.

All gas burners follow the same principle; the force which drives the gas and air into the burner is the pressure of gas in the pipeline (31). A biogas stove can have single or double burner with varying gas consumption rates ranging from $220 \mathrm{dm}^{3} \mathrm{~h}^{-1}$ to $450 \mathrm{dm}^{3} \mathrm{~h}^{-1}$ at standard temperature and pressure $(32,33)$. This consumption rate results from the pressure provided by the biogas plant and the diameter of the inlet pipe. The jet at the inlet of the burner increases the gas speed, so producing a draft that sucks primary air into the pipe.

The stove must be designed to suit basic local requirements such as ease of cleaning, repair, good burning properties, safe to use, versatility, attractive appearance (33). However, these requirements vary from location to location and are linked to local dietary and hence cooking requirements. The gas demand is higher in cultures with complicated cuisine and where whole grain maize or beans are part of the staple diet.

The overall efficiency of using biogas is $45 \%$ in stoves (34,35), $24 \%$ in engines and $3 \%$ in lamps (26). The efficiency of the given biogas stoves is not constant. It varies depending on the surrounding conditions; wind, temperature, pressure, shape, specific heat capacity and weight of vessel, burner size of stove and size of bottom face of cooking vessel, and the quality of the gas (36) (see Table 1).

\section{Table 1 - Comparison of efficiency of different types of stoves}

\subsection{Tests on biogas burners}

Eight biogas stoves were tested by the Centre for Research in Energy and Energy Conservation (CREEC) at Makerere University in July 2012. CREEC was set up to test improved wood stoves using equipment supplied by Aprovecho. The stoves were manufactured in Uganda and were supplied by Heifer International-Uganda. Most of the stoves were made to a similar design, as shown in the photograph in Figure 3. The stoves were supplied with gas from a fixed dome biogas plant and used to boil a 5 litre pot of water (37).

\section{Figure 3 - Photograph of the type of stove tested}

The dimensions of the stoves were tested against the above theory. The measurements are given in Table 2 and the results of the calculations in Table 3 . The calculations were made assuming a gas pressure of $137 \mathrm{~Pa}$. The gas pressure from a fixed dome plant is variable, so the power output from the burners is also variable. The flames are usually adjusted by a gas valve, which chokes the flow into the burner and reduces the effective pressure at the burner jet.

Table 2 - Key dimensions of 8 stoves

Table 3 - Design checks on 8 stoves 
The power output from these burners seems high. An electric kettle uses a $3 \mathrm{~kW}$ element, so a power of over $5 \mathrm{~kW}$ seems excessive. This suggests that the jet sizes are too big. However, the calculations were based on a value for the coefficient of discharge $\left(C_{d}\right)$ of 0.8 . If the jets are poorly made and have rough edges, the value of $C_{d}$ may be lower. The entrainment ratio seems reasonable for most of the stoves, as the primary aeration is between $50 \%$ and $85 \%$. The aeration for the Large Psem stove is much too high, while that for the small Psem stove is too low. Aeration can be reduced by adjusting the size of the air holes with a movable cover that partially blocks these holes.

None of these stoves meets the Priggs test, that the flame port area $\left(A_{p}\right)$ is between 1.5 and $2.2 \times$ the throat area $\left(A_{t}\right)$. This calls into question whether the primary aeration is working properly. Flame ports that are too small give a high back pressure on the flow of the gas mixture through the burner. The flame port areas should be much higher in all of the burners. Also the mixing tube length is too short, even for those stoves that use a venturi shape; the mixing tubes should be at least 6 times the throat diameter, preferably 10 times.

The stoves were used to heat 5 litres of water from ambient temperature to $96^{\circ} \mathrm{C}$ and the time it took recorded. Taking ambient temperature as $27^{\circ} \mathrm{C}$, this required $1.425 \mathrm{MJ}$ of energy, ignoring the heat capacity of the pan. The gas flow was measured and, assuming an average enthalpy of combustion for biogas of $21.7 \mathrm{MJ} \mathrm{m}^{-3}$, the actual power of each stove could be calculated, as shown in Table 4 . Following the Aprovecho protocol (designed for improved wood stoves) the tests were done when the stove was cold and then again when the stove had been heated up by the first test.

\section{Table 4 - Results of boiling tests on 8 stoves}

The overall efficiency values seem low, as Chinese and India standards define $55 \%$ as the minimum required (32). The variation between hot and cold results appears inconsistent, as the gas flow rate for the hot tests are higher for some stoves and lower for others. However, the stove is turned off at the gas tap between tests. It is very difficult to set the tap at exactly the same position between tests, so the pressure at the jet may have been different for the cold and hot runs for some of the stoves. The two flow rates were the same for the Bremmen stove, but the efficiency of the stove was lower for the hot test. Stove efficiency has two components, the efficiency of combustion of the gas and the efficiency in which the heat is transferred to the pot. Poor combustion is indicated by the formation of carbon monoxide, which indicates the gas is poorly mixed with air and does not burn properly. Carbon monoxide and carbon dioxide were measured in the tests and the results are shown in Table 5.

\section{Table 5 - Results of combustion tests on 8 stoves}

The results show very high carbon monoxide levels for most of the stoves. Indian and Chinese standards require less than $0.05 \%$ of $\mathrm{CO}$ in the smoke (32), so all the stoves fail apart from the small Psem stove. The small Psem stove has the lowest primary aeration. There is no correlation between the CO levels and the overall stove efficiency. However, poor combustion is likely to be a strong contributor to the low overall efficiency figures.

Poor heat transfer between the flames and the pot is a result of poor frame design. The frame supports the burner and also holds pots at the right distance away from the flames. The optimum value for the height of a pot above the flame ports is between 22 and $42 \mathrm{~mm}$ (38). The values for the stove on test all fall within this range, apart from the Large Psem stove. However, the flame ports are on the side of the manifold cap, so the distance between the flame ports and the pot is greater than the measured value between the manifold cap and the pot.

The relative diameter of the circle through the flame ports and that of the pot is another factor. A large source of heat under a small pot means that heat is wasted. A small heat source under a large pot allows cold air from below to mix with the hot gases flowing up the side of the pot. The pot used in the tests was $270 \mathrm{~mm}$ in diameter, while the diameters of the circle on which the flame ports sit are much smaller in most of the stoves. This suggests the second factor may explain some of the heat losses. 


\subsection{Safety of the stoves}

Only one of the stoves had four legs, while the rest had three legs. The advantage of three legs is that the stove remains stable, even if the surface on which it is placed is uneven. A four legged stove will tend to wobble, unless it is on a flat surface. The three legged stoves also had a circular frame, but this meant they could be tipped over more easily if they were knocked. Short legs meant the frame was more stable, but at the cost of causing the surface on which the stove sits to heat up. The KEJ stove had the shortest legs, but also had the smallest frame. A small frame means that it is close to the flame ports and the edges can heat up and cause burns to people, especially children, who touch it.

\subsection{Discussion and burner design modification}

The results of these tests offer similar conclusions to the ones done by SNV on burners made by different biogas projects, such as those in Nepal, Bangladesh, Lesotho and Rwanda (32). The quality of such stoves does not meet the standards defined in China and India. However, the quality of the stoves tested in Uganda seems to be worse than those tested by SNV.

In general, the stoves should be made larger, which would allow several problems to be overcome. A larger diameter frame would make it more stable and allow the legs to be made longer. This would reduce heat transfer to the frame and the surface on which the stove is placed. A larger frame would allow the use of a longer mixing tube and a larger diameter for the burner manifold.

The gas flow through the jet is critical to the performance of a stove. If the flow is correct, the efficiency can be as high as $60 \%$ (36). However, the pressure from a fixed dome plant is variable, so the flow needs to be adjusted as the pressure changes. The tests done for SNV suggested that the jet sizes in those stoves were too small (32). The jet diameters were between 2 and $3 \mathrm{~mm}$.

The main parameters for designing a biogas stove are efficiency and safety. The main factors to be considered in order to achieve high efficiency of the stove are composition and pressure of the gas, velocity of the flame and pan to burner distance are important factors to be considered (30). However, the stove should also meet the following criteria:

- Gas inlet pipe should be smooth to minimize the resistance to flow of gas and air.

- Spacing and size of air holes should match with the requirement of gas combustion.

- Volume of burner manifold should be large enough to allow complete mixing of gas with air.

- Size, shape and number of burner port holes should allow easy passage of the gas-air mixture, formation of a stable flame and complete combustion of gas, without causing the flame to lift off the burner port or back flash from the burner port to gas mixing tube and injector jet. The flame should be self stabilizing, i.e. flameless zones must re-ignite automatically within 2 to 3 seconds.

- Under ideal condition, the pot should be cupped by the outer cone of the flame without being touched by the inner cone.

- Size and shape of the burner should match the cooking vessels.

The tests on the Ugandan stoves suggest that the jet sizes (between 5 and $8 \mathrm{~mm}$ ) are too big. An ideal approach would be to use a needle valve that uses a fine tapered needle mounted on a threaded rod. The rod can be turned by a knob to insert the needle into the jet to change its size. However, needle valves are very difficult to make accurately.

\section{Figure 4: Modified gas burner design}

The main issue appears to be that the mixing tubes are too short and the flame port area is too small. The mixing tube should be made longer, so that it extends well beyond the edge of the frame. The diameter of the burner manifold needs to be larger, so that a greater number of flame ports can be drilled in the cap. The burner manifold could be made in a donut shape, with a hole in the centre. Flame ports can be 
placed on the inner surface of the ring as well as on the outside surface. Secondary air can then flow up the centre of the donut ring as well as around the outside.

A modified burner design is shown in Figure 3. This uses a jet size of $4 \mathrm{~mm}$, giving a nominal power output of $3.3 \mathrm{~kW}$ at a gas pressure of $137 \mathrm{~Pa}$. The throat size is $20 \mathrm{~mm}$, which gives an entrainment ratio of 3.88 and a primary aeration of $70 \%$. The mixing tube is $200 \mathrm{~mm}$ in length (i.e. 10 times the throat diameter). On the donut shaped manifold, there are 90 flame ports of $3.0 \mathrm{~mm}$ diameter, 60 on the outside of the donut and 30 on the inside. This gives a total flame port area of $679 \mathrm{~mm}^{2}$, which is 2.16 times the throat area, which is within the Priggs range.

\subsubsection{Modification of high pressure stoves}

LPG stoves can be modified to fit the properties of biogas. However, the efficiency is not as good as with a stove designed specifically for biogas. Compared to other gases, biogas needs less air for combustion. Therefore, conventional gas appliances need larger gas jets when they are used for biogas combustion.

Overall efficiency of a stove depends on operating conditions, including temperature; pressure; wind speed; specific heat capacity, bottom and overall shape, weight, and size of vessel; and amount of specimen. Thus different tests for efficiency could yield different results for the same stove.

Biogas requires less air for complete combustion than LPG. This means that for the same quantity of air, more biogas is required. To achieve this in a stove, the diameter of the jet nozzle should be increased using a drill from $1.2 \mathrm{~mm}$ to $1.6 \mathrm{~mm}$, so reducing the output speed of the gas. This will reduce the suction of primary air, which will reduce the amount of air in the mixture. One $\mathrm{dm}^{2}$ of biogas requires $5.7 \mathrm{dm}^{3}$ of air for complete combustion, while butane and propane require 30.9 and $23.8 \mathrm{dm}^{3}$ of air, respectively (26).

Gas stoves can be manufactured by most blacksmiths or metal works. The gas burner is usually made of high quality steel, cast iron or clay. The design of a pot-stand must be sufficiently strong to meet food preparation methods of different communities, for example to allow stirring of thick foods such as millet bread, rice, ugali, injera, matooke and stew.

\section{Biogas lamps}

In villages without electricity, lighting is not only a basic need, but also a status symbol. However, biogas lamps currently provide little relief as they are not very energy-efficient and tend to get very hot, this excess heat is a by-product.

Biogas lamps can be used to generate light by combustion of the gas (39). The gas lamp consists of gas inlet hole, an air inlet hole, an air inlet adjustment valve, a mixing tube, a fire resistant clay head and gauze mantle. The mantle holder consists of a gas nozzle for the flow of combustible gas and air holes for proper mixing of gas and air. The burning gas heats a mantle until it glows brightly. Reflectors are fitted on top of the lamp, heat and light produced at the mantle is reflected below and the flow of heat through the lamp top is retarded.

The flame from the lamp has to be regulated in such a way that the hottest part of the flame matches the form of the mantle. Proper air mixture and appropriate size of the mantle play the biggest roles. The methane content of biogas sometimes changes. Therefore, brightness of the light will also change.

The performance of a biogas lamp is dependent on optimal tuning of the gas mantle and the shape of the flame at the nozzle. The mantle should be surrounded by the hottest core of the flame at the minimum gas consumption rate. If the mantle is too large, it will show dark spots; if the flame is too large, gas consumption will be too high for the light-flux yield. The lampshade reflects the light downward, and the glass prevents the loss of heat (40). 
Biogas lamps have a consumption rate of $120-150 \mathrm{dm}^{3} \mathrm{~h}^{-1}$, with an average light output of 600 lumens and with an efficacy that varies from $0.48-0.94 \mathrm{Im}$ watt $^{-1}(4,41)$ (see Table 6 ). A biogas lamp is only 3 percent efficient; most of the energy is lost in form of waste heat (42).

Table 6 - Ranges of luminous efficacy, flux and fuel use that can be expected from different flamebased and electric lamps

\subsection{Modification of a biogas lamp}

Biogas lamps are controlled by adjusting the supply of gas and primary air. The aim is to make the gas mantle burn with uniform brightness and a steady, popping low sound. This can be checked by placing the glass on the lamp and waiting 2-5 minutes, until the lamp has reached $1,000-1,500{ }^{\circ} \mathrm{C}$; the operating temperature (43). Most lamps operate at a gas pressure of $0.49-1.47 \mathrm{kPa}$. If the pressure is any lower, the mantle will not glow; if the pressure is too high (fixed-dome biogas plants) the mantle may tear.

Steps used to adjust a biogas lamp are as follows:

1. Pre-control of the supply of biogas and primary air without the mantle, to produce, at the outset, an elongated flame with an extended inner core.

2. Fine tuning the flame with the incandescent body in place, to produce an intensely glowing incandescent body, coupled with slight further fine-tuning of the air supply.

Kerosene pressure lamps can be modified to use biogas. The jet in the kerosene pressure lamps is enlarged and a new mixing pipe is mounted. The gas is connected via the original pump opening. Instead of a consumption rate of $0.09 \mathrm{dm}^{3} \mathrm{~h}^{-1}$ for kerosene, $186 \mathrm{dm}^{3} \mathrm{~h}^{-1}$ biogas is consumed (40).

\subsection{Shortcomings of commercial-type biogas lamps}

Commercially available gas lamps are not optimally designed for the specific conditions of biogas combustion i.e. fluctuating pressure and variable gas composition. The most frequently observed shortcomings are excessively large nozzle diameters and gas mantles, no possibility of changing the injector, and poor means of combustion-air control. Such drawbacks result in unnecessarily high gas consumption and poor lighting.

\section{Biogas-fuelled engines}

Biogas is an alternative fuel for internal combustion engines and gas turbines to generate electricity. However, it has a low enthalpy of combustion (44). Electricity generation consists of burning the gas in an engine; exhaust heat is generated and can be recovered for powering a refrigeration process (45). Normally, a biogas driven engine requires a considerable amount of gas. Internal combustion engines are used if the gas at the site is capable of producing 1-3 MW of electricity; otherwise a gas turbine is chosen (46). As a rule of thumb, a biogas plant that will be used for fuelling engines should produce at least $10,000 \mathrm{dm}^{3}$ of gas per day $(33,42)$. Biogas will not auto-ignite; a pilot injection of liquid fuel is required to start ignition (47).

Diesel engines draw in air and compress it at a ratio of about 17:1 to a pressure of approximately $3 \mathrm{Mpa}$ and a temperature of $700^{\circ} \mathrm{C}$. The fuel charge is injected after the air is compressed and ignites itself at this temperature. The power output is controlled by varying the amount of fuel that is injected, while the air intake remains constant (42).

Traditional spark ignition engines draw in a mixture of fuel and the required amount of combustion air. The charge is ignited by a spark plug at a lower compression ratio in the range of $8: 1$ to $12: 1$. Power is controlled by varying the intake of air via the throttle, and the fuel injection into the air stream is controlled by the carburettor.

\subsection{Modification of engines}


Biogas contains $\mathrm{CO}_{2}$, water vapour and hydrogen sulphide; the composition of biogas must be considered while designing and or modifying spark-ignition engines. Appropriate engine types for conversion to biogas fuels are four-stroke diesel engines or spark ignition engines, requiring little modification compared to natural gas engines. These are available in standard versions with power ratings from $1 \mathrm{~kW}$ to $100 \mathrm{~kW}$. Less suitable for conversion to biogas fuel are two-stroke engines in which the lubrication is achieved by adding oil to the liquid fuel (45).

Petrol engines can use biogas with relatively simple modifications, but the compression ratio of the engine will be too low to produce optimum operation. Diesel engines can be converted to full biogas operation by lowering the compression ratio and installation of the spark ignition system $(42,45)$.

The pressure of the biogas used in an engine is important. A carburettor works by inducing a pressure that is slightly lower than atmospheric to draw the gas into the engine. If the biogas pressure is too high (more than 2-4 Pa), excess gas can be induced, making the engine inefficient. Gas pressure control valves may need to be used, to keep the gas pressure in the right range.

Engines can be modified in the following ways:

- Diesel engines in dual-fuel mode, for use with a mixture of diesel fuel and biogas

- Diesel engines converted to a spark ignition engine, for use with pure biogas

- Carburetted spark ignition engines converted for use with pure biogas

- Fuel Injection gasoline engines converted for use with pure biogas

Small scale generator modifications can be very difficult to achieve. Large generators are not designed to be portable or light weight, but personal sized units are. This can make modification very difficult, since valves and other parts may be inaccessible, or may not have room available for modifications.

\section{Refrigerators}

An absorption refrigerator uses a heat source, for example biogas, solar or LPG to provide the energy needed to propel the cooling system. The absorption refrigeration process uses three components; the evaporator, the condenser, and the expansion valve. These components function in exactly the similar manner as the vapour compression system. However, as an alternative of the mechanical compressor, it exploits a thermal compressor.

\subsection{Modification of commercial refrigerators}

The burner in an absorption refrigerator must be modified to use biogas as the energy source. Whenever a refrigerator is converted for operating with biogas, care must be taken to ensure that all safety features function properly. Remote ignition via a piezoelectric element substantially increases the ease of operation (48). A design of such a burner was successfully tested at Nepalgunj, Rupandehi district in Nepal (49). With a gas pressure of $8 \mathrm{~cm}$ water $(785 \mathrm{~Pa})$ and gas consumption of $100 \mathrm{dm}^{3} \mathrm{hr}^{-1}$, this burner has worked to run a $340 \mathrm{dm}^{3}$ refrigerator. Modifications must ensure that the combustion is safe and controlled. Inadequate modifications may cause the performance of the equipment to deteriorate or may even lead to total failure.

\subsection{Biogas requirements at household level}

For $100 \mathrm{dm}^{3}$ refrigeration volume, about $2,000 \mathrm{dm}^{3}$ of biogas is required per day, depending on outside temperatures. A larger household refrigerator consumes about $3,000 \mathrm{dm}^{3}$ per day (42).

\section{Radiant heaters and incubators}

Infrared heaters are used in agriculture for achieving the temperatures required for raising young stock, such as piglets and chickens in a limited amount of space. The nursery temperature for piglets begins at 
$30-35^{\circ} \mathrm{C}$ for the first week and then gradually drops off to an ambient temperature of $18-23^{\circ} \mathrm{C}$ in the fourth or fifth week. As a rule, temperature control consists of raising or lowering height of the heater. Good ventilation is important in the stable or nursery in order to avoid excessive concentrations of carbon monoxide or $\mathrm{CO}_{2}$. As a result, the animals must be kept under regular supervision, and the temperature must be checked at regular intervals. Heaters for pig or chicken rearing usually require approximately 200-300 dm $\mathrm{dm}^{3}$.

\subsection{Thermal radiation of heaters}

Radiant heaters develop their infrared thermal radiation through a ceramic body that is heated to 600 $800^{\circ} \mathrm{C}$ (red-hot) by the biogas flame. The heating capacity of the radiant heater is defined by multiplying the gas flow by its net calorific value, since $95 \%$ of the energy content of biogas is converted to heat. Small-heater outputs range from 1.5 to $10 \mathrm{~kW}$ thermal power.

\subsection{Gas pressure}

Commercial-type heaters are designed for operating on butane, propane and natural gas at a supply pressure of between 3 and $8 \mathrm{MPa}$. Since the primary air supply is factory-set, converting a heater for biogas use normally consists of replacing the injector. Experience shows that biogas heaters rarely work satisfactorily because the biogas has a low net calorific value and the gas supply pressure is below $2 \mathrm{MPa}$. The ceramic panel, therefore, is not adequately heated, i.e. the flame does not reach the entire surface, and the heater is very susceptible to draft.

\subsection{Safety pilot and air filter}

Biogas-fuelled radiant heaters should always be equipped with a safety pilot, which turns off the gas supply if the temperatures falls i.e. the biogas is not burning. An air filter is required for sustained operation in dusty barns.

\subsection{Incubators}

Incubators are used to imitate and maintain optimal hatching temperatures for eggs. They are used to increase brooding efficiency. Indirectly warm-water-heated planar-type incubators, in which a burner heats water in a heating element for circulation through the incubating chamber, are suitable for operating on biogas. The temperature is controlled by ether-cell-regulated vents $(39,50)$.

\section{Discussion}

The emphasis of this paper has been on the technical issues related to the use of biogas appliances in SSA. Further work is required to consider other issues, which may also impede the use of biogas most effectively in rural areas in SSA.

Issues that must be considered further to increase accessibility of biogas technology to the rural poor are:

a) Can the poor afford the initial investment and maintenance costs of biogas appliances?

b) Do the poor have access to finance/credit?

c) Is there commitment from national governments in support local manufacture of biogas appliances?

d) Is there a way to ensure the manufacture biogas appliances is done to a good quality, so they meet clearly defined design standards.

e) Is there potential for reducing cost of biogas appliances by working at a larger scale? What potential is there for improving cost-effectiveness?

f) What is the efficiency of biogas appliances under operation in different locations of SSA?

g) What is the actual calorific value of biogas? 
600

601

602

603

604

605

606

607

608

609

610

611

612

613

614

615

616

617

618

619

There is a need for further research into behavioural studies (choices and preferences), including experimental economics, quantification issues (capturing various costs and benefits of components), socio-economic design mechanisms, barriers to uptake, knowledge transfer (awareness, training, and participation).

\section{Conclusions}

Biogas has become an important alternative fuel because it is an integrated system with multiple benefits, including diversification of cooking fuel supply, reduction of local pollutants, improved indoor air quality, sanitation and crop yield improvement. The challenge does not lie in the development of the small-scale biogas digesters; the processes of digestion are already well understood and different designs for lowcost digesters are operational. What is needed is the research to improve and document performances of different biogas appliances in SSA.

Many of the locally available gas burners that were tested were shown to be of poor quality: they had low efficiencies and were shown to be made to designs that did not follow gas burner theory adequately. The range of potential applications for biogas, as a rural energy source, is high. If equipment can be made locally that is of a higher quality and able to meet well defined design standards and also be affordable, biogas technology can have a much greater impact on rural livelihoods in rural areas of SSA.

\section{Acknowledgement}

The authors are grateful to DFID for the financial support granted through The New and Emerging Technologies Research Competition (NET-RC). We also want to thank numerous authors, staff at CREEC and Uganda Domestic program who work tirelessly to provide the know-how, books, articles on biogas technology whose works were made reference to.

\section{REFERENCES}

1. Legros G, Havet I, Bruce N, Bonjour S. The Energy Access Situation in Developing Countries: A Review Focusing on the Least Developed Countries and Sub-Saharan Africa. New York, USA: UNDP/WHO; 2009 Nov p. 130. Available from: http://content.undp.org/go/cmsservice/download/asset/?asset_id=2205620

2. Davidson O, Chenene M, Kituyi E, Nkomo J, Turner C, Sebitosi B. Sustainable Energy in SubSaharan Africa. Seychelles: International Council for Science: Regional Office for Africa; 2007 Mar. Available from: http://www.icsu.org/africa/publications/ICSUROASciencePlanonSustainableEnergy.pdf.

3. Mapako M, Mbewe A. Renewables and Energy for Rural Development in Sub-Saharan Africa. Plymouth, UK: Zed Books; 2004. 395 p. Available from: http://zedbooks.co.uk/node/13217

4. Mills E. The $\$ 230$-billion Global Lighting Energy Bill. Nice, France: International Association for Energy-Efficient Lighting and Lawrence Berkeley National Laboratory; 2002. Available from: http://evanmills.Ibl.gov/pubs/pdf/global_lighting_energy.pdf.

5. Rajvanshi AK . R\&D strategy for lighting and cooking energy for rural households. Curr Sci. 2003;85(4):437-43.

6. Evans M. The specter of fuel-based lighting,. Sci J. 2005;308:1263-4.

7. Kamfor Co Ltd. Study on Kenya's Energy Demand, Supply and Policy Strategy for Households. Nairobi, Kenya: Small-Scale Industries and Service Establishments, Ministry of Energy; 2002.

8. Jones R, Du J, Gentry Z, Gur I, Evans M. Alternatives to fuel-based lighting in rural China. Shanghai; 2005. Available from: http://light.lbl.gov/pubs/rl6_id058-final.pdf 
9. IEA (International Energy Agency). World energy outlook. 2002. Available from: http://www.worldenergyoutlook.org/media/weowebsite/2008-1994/weo2002_part1.pdf

10. World Bank Group Energy Sector strategy. Background paper addressing the electricity gap. 2010. Available from: http://siteresources.worldbank.org/EXTESC/Resources/Addressing_the_Electricity_Access_Gap.pd $f$

11. WHO. Working together for health. 2006. Report No.: ISBN 924156317 6,. Available from: http://www.who.int/whr/2006/en/

12. Bruce N, Perez-Padilla R, Albalak R. Indoor air pollution in developing countries: A Major environmental and public health challenge. Bull World Health Organ. 2000;78(9):1078-92.

13. Fullerton DG, Semple S, Kalambo F, Suseno A, Malamba R, Henderson GD. Biomass fuel use and indoor air pollution in homes in Malawi. Occup Env Med. 2009;66:777-83.

14. Kurmi OP, Semple S, Steiner M, George D, Henderson AJ. Particulate matter exposure during domestic work in Nepal. Ann Occup Hyg. 2008;52(6):509-17.

15. McCracken J, Smith K, Stone P, Díaz A, Arana B, Schwartz J. Intervention to lower household wood smoke exposure in Guatemala reduces ST-segment depression on electrocardiograms. 2011. Available from: http://ehs.sph.berkeley.edu/krsmith/publications/2011/2011_ST_EHP.pdf

16. Northcross A, Mann J, Jenny A, Chowdhury Z, Canuz E, Smith K, et al. Wood Smoke Exposure and Respiratory Health With and Without an Improved Chimney Stove in Rural Guatemala. Epidemiology. 2011;22(1):S202-206.

17. Austin G, Blignaut J. South African national rural domestic biogas feasibility assessment. Ministry of Development Co-operation, the Netherlands; 2008.

18. Verstraete W, Morgan-Sagastume F, Aiyuk S, Waweru M, Rabaey K, Lissens G. Anaerobic digestion as a core technology in sustainable management of organic matter. Water Sci Technol. 2005;52(1-2):59-66.

19. Singh KJ, Sooch S. Comparative study of economics of different models of family size biogas plants for state of Punjab, India. Energy Convers Manag. 2004;45:1329-41.

20. Igoni $\mathrm{AH}$, Ayotamuno MJ, Eze CL, Ogaji SOT, Probert SD. Designs of Anaerobic Digesters for Producing Biogas from Municipal Solid-Waste. Appl Energy. 2007;85:430-8.

21. Angelidaki I, Ellegaard L, Angelidaki I, Ellegaard L. Codigestion of manure and organic wastes in centralized biogas plants. Status and future trends. Appl Biochem Biotechnol. 2003;109:95-105.

22. Ni J-Q, Nyns E-J. New concept for evaluation of biogas management in developing countries. Energy Convers Manag. 1996;37:1525-34.

23. Han JL, Mol APJ, Yonglong L, Zhang L. Small-scale fuel wood projects in rural China lessons to be learnt. Energy Policy. 2008;36:2154-62.

24. Lantz M, Svensson M, Bjornsson L, Bjornsson P. The prospects for an expansion of biogas systems in Sweden incentives, barriers and potentials. Energy Policy. 2007;35(3):1830-43.

25. Mwakaje AG. Dairy farming and biogas use in Rungwe district, south-west Tanzania: A study of opportunities and constraints. Renew Sustain Energy Rev. 2008;12:2240-52. 
26. Sasse L, Kellner C, Kimaro A. Improved Biogas Unit for Developing Countries. GATE, GTZ Germany; $1991 . \quad$ Available from: http://www.gateinternational.org/documents/publications/webdocs/pdfs/g33ime.pdf

27. UNEP (United Nations Environment Programe). PoA manual for mini biogas plants for households. 2009. Available from: cd4cdm.org/publications/poamanualbiogashouseholds.pdf

28. Mateescu C, Barab G, Babutanu CA. Opportunities and Barriers for development of biogas technologies in Romania. Environ Eng Manag J. 2008;7(5):603-7.

29. Energy4All. Brief progress and planning report the Working Group on Domestic Biogas. 2012; Available from: http://www.energyforall.info/domestic-biogas-working-group/

30. Fulford DJ. Running a Biogas Programme: A handbook. London: Practical Action Publications (Intermediate Technology Publications); 1988. Available from: http://developmentbookshop.com/running-a-biogas-programme-pb

31. Fulford DJ. Biogas stove design. University of Reading, UK; 1996. Available from: http://www.kingdombio.com/BiogasBurner1.pdf

32. Khandelwal KC, Gupta VK. Biogas stove and lamp test Report. SNV Publications, Netherlands; 2009. Available from: http://m.snvworld.org/en/publications/test-reports-on-biogas-stoves-andlamps-prepared-by-testing-institutes-in-china-india

33. APCAEM. Recent developments in biogas technology for poverty reduction and sustainable development. Beijing, China: ESCAP; 2007 p. 73. Available from: http://www.uncsam.org/publication/F-Biogas.PDF

34. George R. Commercialization of technology for domestic cooking applications. New Delhi: TERI (The Energy and Resources Institute); 1997. p. 299-230. Available from: http://www.worldcat.org/title/biomass-energy-systems-proceedings-of-the-international-conference26-27-february-1996-new-delhi/oclc/37443254

35. Smith KR, Klialil MAK, Rasmussen RA, Apte M, Manegdeg F. Greenhouse gases from biomass and fossil fuel stoves in developing countries: A Manila pilot study. Chemosphere. 1993;16(1-4):479_ 505.

36. Shrestha JN, Sing RB, Pradhan S, Paudyal BB. Final report on efficiency measurement of biogas stoves. Center for Energy Studies Institute of Engineering, Tribhuvan University; 2004. Available from:

http://www.snvworld.org/sites/www.snvworld.org/files/publications/efficiency_measurement_biogas_ stoves_nepal_2004.pdf

37. Bailis R, Ogle D, MacCarty N, Still D. The Water Boiling Test Version 4.1.2 Cookstove Emissions and Efficiency in a Controlled Laboratory Setting. Oregan: Aprovecho; 2009. Available from: http://www.aprovecho.org/lab/index.php?option=com_rubberdoc\&view=doc\&id=231\&format=raw

38. Chandra A, Tiwari GN, Srivastava VK, Yadav YP, Khas H. Performance Evaluation of Biogas Burners. Energy Convers Manag. 1991;32(4):353-8.

39. Dishna S, Elmar D, George C B. Lighting technologies. 2005. Available from: http://www.ppre.unioldenburg.de/download/Downloads/Lighting_Technologies_1.pdf. 
40. Kossmann W, Habermehl S, Hörz T, Krämer P, Klingler B, Kellner C, et al. Biogas Basics. Germany: ISAT and GTZ; 1999. Available from: http://www.susana.org/langen/library?view=ccbktypeitem\&type $=2 \& i d=526$

41. Rubab S, Kandpal TC. Financial evaluation of SPV lanterns for rural lighting in India. Sol Energy Mater Sol Cells. 1996;44(3):261-70.

42. Werner U, Stöhr U, Hees N. Biogas plants in animal husbandry. GTZ, GATE; 1989. Available from: http://www.gate-international.org/documents/publications/webdocs/pdfs/g32bie.pdf

43. Ter Heegde F. Appliances for domestic biogas plants. Oldenburg: SNV Netherlands Development Organisation; 2011. Available from: http://www.ppre.unioldenburg.de/download/Biogas/Biogas2011/presentations/04_20110427_Biogas_appliances.pptx

44. Bari S. Effect of carbon dioxide on the performance of biogas/diesel dual-fuel engine. Renew Energy. 1996 Sep;9(1-4):1007-10.

45. Podorson D. Feasibility study on a biogas powered poly-generation system in rural and peri-urban areas in Uganda. Master's thesis: EGI-2011-024MSC EKV837. Stockholm, Sweden: Royal Institute of Technology; 2010.

46. Bade SSO, Guruprasath N. Landfill gas with hydrogen addition- a fuel for SI engines. Fuel. 2008;87:3616-26.

47. Karim GA, Evans RL (Ed). The dual fuel engine. Automotive Engine alternatives. New York: Plenum Press; 1987.0 p. 83-104. Available from: http://books.google.co.uk/books/about/Automotive_engine_alternatives.html?id=8KVTAAAAMAAJ\&r edir_esc=y

48. Granryd E, Ekroth I, Lundqvist P, Melider A, Palm B, Rohlin P. Refrigeration Engineering. Stockholm, Sweden: Department of Energy Technology, Royal Institute of Technology; 2005.

49. Gurung B. Training report of slurry extension officers. BSP/N. SNV Nepal; 1996 p. 208. Available from: www.snvworld.org/files/publications/final_training_report_of_slurry_extension_officers_nepal_1996. pdf

50. Brew-Hammond A, Kemausuor F. Guidebook on modern bioenergy conversion technologies in Africa. 2008. Available from: http://energycenter.knust.edu.gh/downloads/8/80old22.pdf. 
$729 \quad$ Figures

730

731

Figure 1 - Parts of a biogas burner

732

733

734

735

736

737

738

Figure 2 - Parts of a gas flame

Figure 3 - Photograph of a typical stove

Figure 4 - Improved biogas burner 


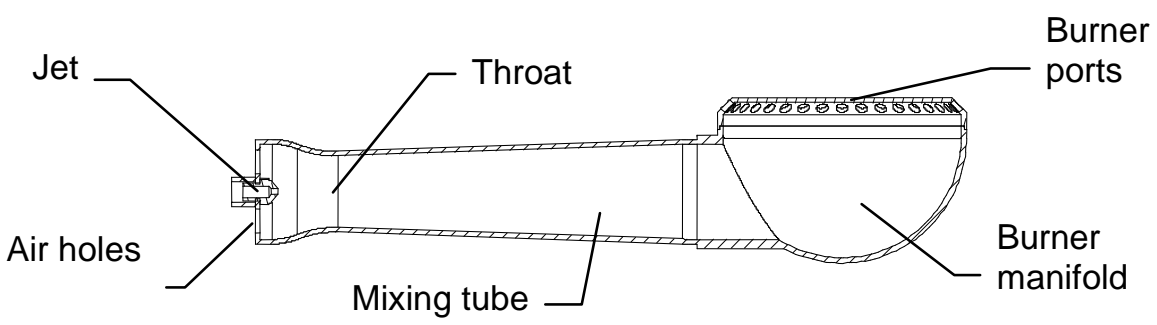

740

741

Figure 1 - Parts of a biogas burner 
742

743

744

745

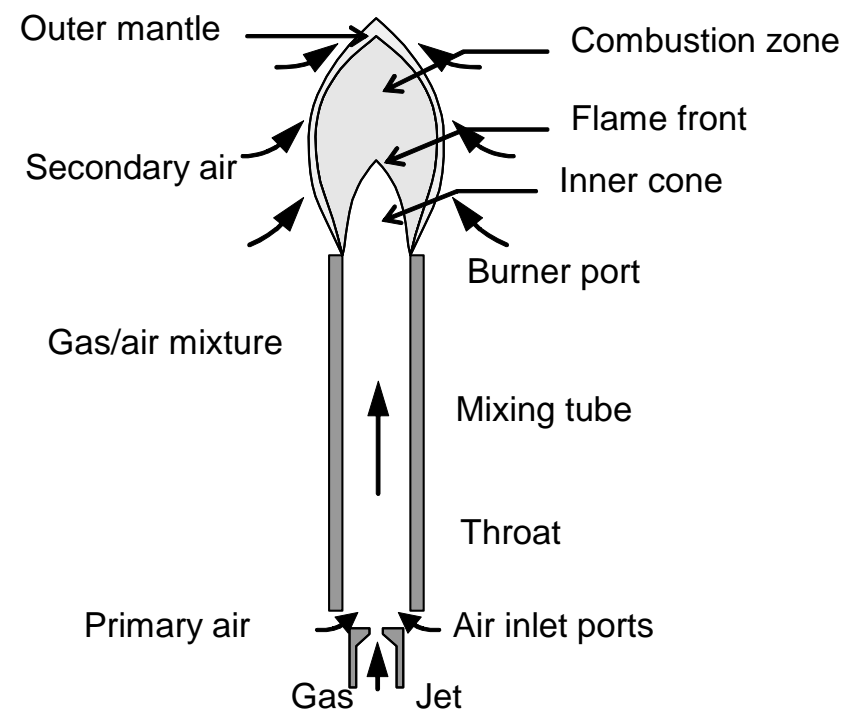

Figure 2: Parts of a gas flame 


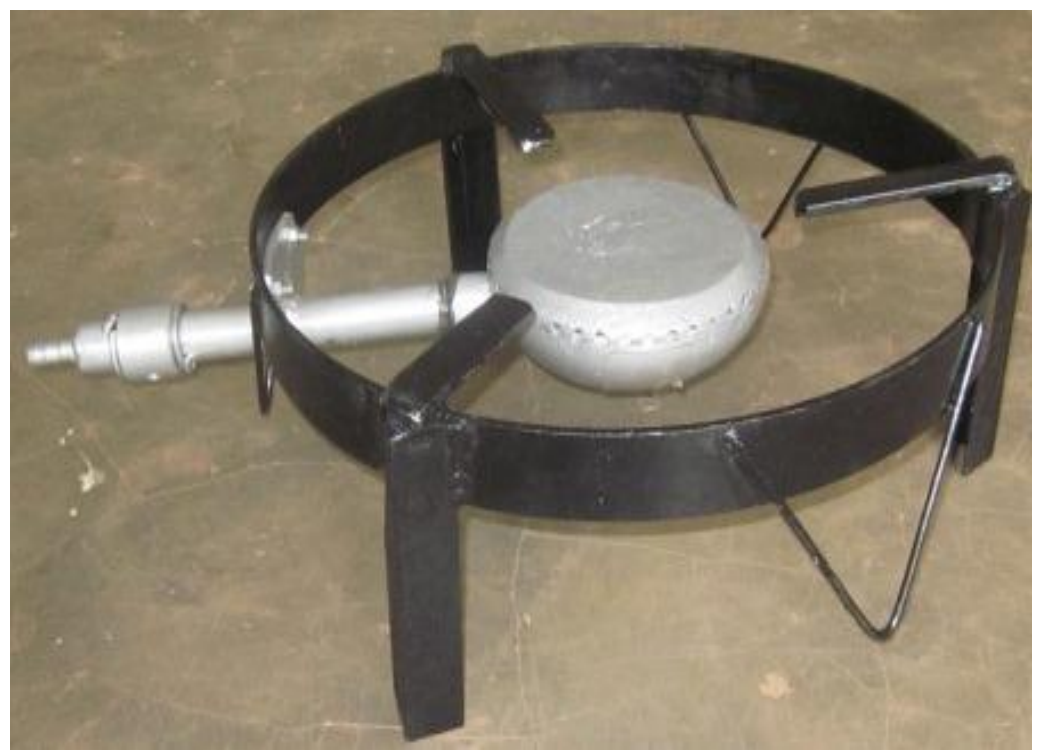

746

747

748

Figure 3: Photograph of the type of stove tested 


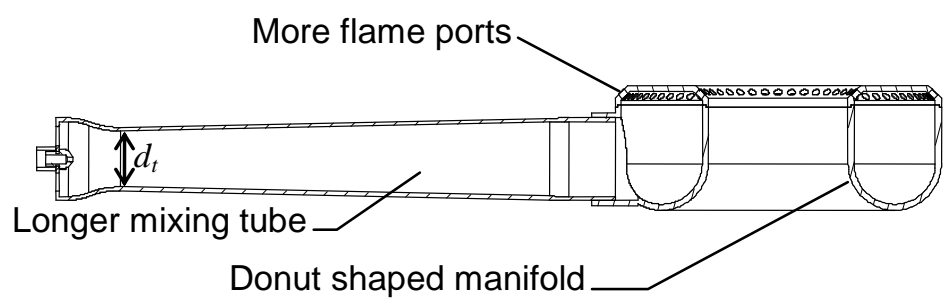

749

750

751

Figure 4: Modified gas burner design 
Tables

754

Table 1 - Comparison of efficiency of different types of stoves

755 Table 2 - Key dimensions of 8 stoves

756 Table 3 - Design checks on 8 stoves

757 Table 4 - Results of boiling tests on 8 stoves

758 Table 5 - Results of combustion tests on 8 stoves

759 Table 6 - Ranges of luminous efficacy, flux and fuel use that can be expected from different flame-based

760 and electric lamps

761 
763 Table 1. - Comparison of efficiency of different types of stoves

764

\begin{tabular}{|l|r|r|}
\hline Fuel/Stove & \multicolumn{1}{|c|}{ Combustion efficiency \% } & Overall efficiency \% \\
\hline Biogas & 99.4 & 57.4 \\
\hline LPG & 97.7 & 53.6 \\
\hline Kerosene & 96.5 & 49.5 \\
\hline Wood & 90.1 & 22.8 \\
\hline
\end{tabular}

765

766 (Source [35]) 
768 Table 2 - Key dimensions of 8 stoves

\begin{tabular}{|l|r|r|r|r|r|r|r|r|}
\hline Parameter & KEJS & Reo & Tusk & Bremen & Ideal & Psem & Double & Psem L \\
\hline Diameter jet $d_{0}(\mathrm{~mm})$ & 5 & 6 & 6 & 5 & 6 & 8 & 6 & 5 \\
\hline Diameter throat $d_{t}(\mathrm{~mm})$ & 24 & 27.5 & 28.2 & 28 & 26.8 & 26.5 & 24 & 38 \\
\hline Area jet $A_{0}\left(\mathrm{~mm}^{2}\right)$ & 19.6 & 28.3 & 28.3 & 19.6 & 28.3 & 50.3 & 28.3 & 19.6 \\
\hline Diameter jet $A_{t}\left(\mathrm{~mm}^{2}\right)$ & 452.4 & 594.0 & 624.6 & 615.8 & 564.1 & 551.5 & 452.4 & 1134.1 \\
\hline Diameter ports $d_{p}(\mathrm{~mm})$ & 5 & 6 & 6 & 6 & 6 & 6 & 2 & 5 \\
\hline Number ports $N$ & 20 & 20 & 20 & 20 & 20 & 21 & 28 & 40 \\
\hline Area ports $A_{p}\left(\mathrm{~mm}^{2}\right)$ & 392.7 & 565.5 & 565.5 & 565.5 & 565.5 & 593.8 & 88.0 & 785.4 \\
\hline Mix pipe length $\left(\mathrm{mm}^{2}\right)$ & 145 & 160 & 158 & 159 & 162 & 149 & 130 & 192 \\
\hline
\end{tabular}

Note: Bremen is short for the Bremmen stove. Psem $L$ is short for the Large version of the Psem stove.

770

771 
773 Table 3 - Design checks on 8 stoves

\begin{tabular}{|c|c|c|c|c|c|c|c|c|}
\hline Parameter & KEJS & Reo & Tusk & Bremen & Ideal & Psem & Double & Psem L \\
\hline Gas Flow $Q$ (litre $\left.\min ^{-1}\right)$ & 14.2 & 20.4 & 20.4 & 14.2 & 20.4 & 36.3 & 20.4 & 14.2 \\
\hline Power $P(\mathrm{~kW})$ & 5.1 & 7.3 & 7.3 & 5.1 & 7.3 & 13.0 & 7.3 & 5.1 \\
\hline Entrainment $r$ & 3.68 & 3.47 & 3.59 & 4.46 & 3.36 & 2.24 & 2.91 & 6.40 \\
\hline Primary aeration $\%$ & 67.0 & 63.2 & 65.2 & 81.1 & 61.1 & 40.8 & 52.9 & 116.3 \\
\hline Priggs test & 0.868 & 0.952 & 0.905 & 0.918 & 1.002 & 1.077 & 0.194 & 0.693 \\
\hline Length/Diam mix tube & 6.042 & 5.818 & 5.603 & 5.679 & 6.045 & 5.623 & 5.417 & 5.053 \\
\hline Gas velocity $\left(\mathrm{m} \mathrm{s}^{-1}\right)$ & 2.82 & 2.69 & 2.76 & 2.28 & 2.63 & 3.30 & 15.13 & 2.23 \\
\hline
\end{tabular}

774

775 
777 Table 4 - Results of boiling tests on 8 stoves

\begin{tabular}{|l|r|r|r|r|r|r|r|r|}
\hline Parameter & KEJS & \multicolumn{1}{c|}{ Reo } & Tusk & Bremen & Ideal & Psem & Double & Psem L \\
\hline Power $P(\mathrm{~kW})$ theory & 5.1 & 7.3 & 7.3 & 5.1 & 7.3 & 13.0 & 7.3 & 5.1 \\
\hline Gas flow (litre/min) Cold & 13.64 & 18.19 & 19.10 & 11.82 & 14.55 & 17.28 & 10.92 & 16.37 \\
\hline Gas flow (litre/min) Hot & 15.46 & 13.64 & 20.01 & 11.82 & 12.73 & 10.92 & 10.01 & 14.55 \\
\hline Power $P(\mathrm{~kW})$ Cold data & 4.89 & 6.52 & 6.84 & 4.24 & 5.21 & 6.19 & 3.91 & 5.87 \\
\hline Power $P(\mathrm{~kW})$ Hot data & 5.54 & 4.89 & 7.17 & 4.24 & 4.56 & 3.91 & 3.59 & 5.21 \\
\hline Heat water $(\mathrm{min})$ Cold & 24.0 & 17.0 & 14.0 & 20.0 & 21.0 & 19.0 & 29.0 & 20.0 \\
\hline Heat water $(\mathrm{min})$ Hot & 21.0 & 19.0 & 15.0 & 24.0 & 29.0 & 27.0 & 30.0 & 22.0 \\
\hline Net Power $(\mathrm{kW})$ Cold & 0.99 & 1.40 & 1.70 & 1.19 & 1.13 & 1.25 & 0.82 & 1.19 \\
\hline Net Power $(\mathrm{kW})$ Hot & 1.13 & 1.25 & 1.58 & 0.99 & 0.82 & 0.88 & 0.79 & 1.08 \\
\hline Efficiency \% Cold Data & $20.2 \%$ & $21.4 \%$ & $24.8 \%$ & $28.0 \%$ & $21.7 \%$ & $20.2 \%$ & $20.9 \%$ & $20.2 \%$ \\
\hline Efficiency \% Hot Data & $20.4 \%$ & $25.6 \%$ & $22.1 \%$ & $23.4 \%$ & $18.0 \%$ & $22.5 \%$ & $22.1 \%$ & $20.7 \%$ \\
\hline
\end{tabular}


781 Table 5 - Results of combustion tests on 8 stoves

\begin{tabular}{|l|r|r|r|r|r|r|r|r|}
\hline Parameter & KEJS & Reo & Tusk & Bremen & Ideal & Psem & Double & Psem L \\
\hline Efficiency \% (average) & $20.3 \%$ & $23.5 \%$ & $23.4 \%$ & $25.7 \%$ & $19.8 \%$ & $21.3 \%$ & $21.5 \%$ & $20.5 \%$ \\
\hline Carbon dioxide $(\mathrm{g})$ & 177 & 55 & 47 & 10 & 20 & 0 & 29 & 80 \\
\hline Carbon monoxide $(\mathrm{g})$ & 470 & 522 & 553 & 383 & 393 & 431 & 365 & 433 \\
\hline Ratio of CO/CO $\%$ & 37.7 & 10.5 & 8.5 & 2.6 & 5.1 & 0.0 & 7.9 & 18.5 \\
\hline CO in smoke \% & 5.6 & 1.6 & 1.3 & 0.4 & 0.8 & 0.0 & 1.2 & 2.8 \\
\hline Pot above burner $(\mathrm{mm})$ & 35 & 30 & 30 & 25 & 35 & 30 & 26 & 10 \\
\hline Diameter of ports $(\mathrm{mm})$ & 65 & 67 & 70 & 72 & 70 & 70 & 130 & 160 \\
\hline Height of frame $(\mathrm{mm})$ & 94 & 120 & 120 & 120 & 121 & 118 & 137 & 160 \\
\hline Diameter frame $(\mathrm{mm})$ & 250 & 268 & 263 & 270 & 270 & 270 & 300 & 400 \\
\hline
\end{tabular}


785 Table 6 Ranges of luminous efficacy, flux and fuel use that can be expected from different flame-based 786 and electric lamps

\begin{tabular}{|l|c|c|c|}
\hline \multicolumn{1}{|c|}{ Light source } & $\begin{array}{c}\text { Luminous flux } \\
\text { (lumen) }\end{array}$ & $\begin{array}{c}\text { Luminous efficacy } \\
\text { (Im/W) }\end{array}$ & Fuel use \\
\hline Candle & 1 to 16 & $0.02-0.22$ & $5.5-7.2 \times 10^{-3} \mathrm{~kg} \mathrm{~h}^{-1}$ \\
Kerosene & $10-100$ & $0.05-0.21$ & $0.02-0.05 \mathrm{dm}^{3} \mathrm{hr}^{-1}$ \\
Hurricane lamp & $220-1300$ & $0.39-1.60$ & $0.06-0.08 \mathrm{dm}^{3} \mathrm{hr}^{-1}$ \\
Pressure lamp & $330-1000$ & $0.94-2.35$ & $2.8-3.4 \times 10^{-3} \mathrm{~kg} \mathrm{hr}^{-1}$ \\
Gas & $330-1300$ & $0.48-0.94$ & $100-200 \mathrm{dm}^{3} \mathrm{hr}^{-1}$ \\
LPG lamp & & & $100 \mathrm{~W}$ \\
Biogas lamp & 500 & 10 to 18 & $20 \mathrm{~W}$ \\
Electric & 400 & 12 to 30 & $13 \mathrm{~W}$ \\
Incandescent (40W) & 600 & 35 to 77 & \\
Halogen (12V/20W) & &
\end{tabular}

(Source [53])

792

793 